\title{
Mortality of patients with acute kidney injury requiring renal replacement therapy
}

\author{
Piotr Czempik1,C,D, Daniel Cieśla ${ }^{2, B}{ }^{1}$, Piotr Knapik ${ }^{3, F}$, Łukasz Krzych ${ }^{1, A, E}$ \\ ${ }^{1}$ Department of Anaesthesiology and Intensive Care, School of Medicine in Katowice, Medical University of Silesia, Poland \\ ${ }^{2}$ Department of Science, Education and New Medical Technologies, Silesian Centre for Heart Diseases, Zabrze, Poland \\ ${ }^{3}$ Department of Cardiac Anesthesiology and Intensive Care, Silesian Centre for Heart Diseases, Zabrze, Poland \\ A - research concept and design; $\mathrm{B}$ - collection and/or assembly of data; $\mathrm{C}$ - data analysis and interpretation; \\ $\mathrm{D}$ - writing the article; $\mathrm{E}$ - critical revision of the article; $\mathrm{F}$ - final approval of the article
}

\section{Address for correspondence \\ Piotr Czempik}

E-mail: pczempik@sum.edu.pl

\section{Funding sources}

None declared

Conflict of interest

None declared

\section{Acknowledgements}

We acknowledge the contribution made by departments that regularly report to the Silesian Registry of ICUs. Special thanks should be given to professors Hanna Misiołek and Dariusz Maciejewski, and to doctors Danuta Gierek, Agnieszka MisiewskaKaczur and Andrzej Moczała.

Received on April 30, 2016

Reviewed on June 19, 2016

Accepted on September 06, 2016

\begin{abstract}
Background. Acute kidney injury (AKI) in critically ill patients has a deleterious impact on the prognosis, especially when renal replacement therapy (RRT) is required. This issue has not yet been investigated in the intensive care setting in Poland.

Objectives. The aim of the study was to evaluate the short-term outcomes of AKI-RRT subjects, based on a large registry population.

Material and methods. This observational multicenter study covered 100 demographic and clinical variables from the Silesian Registry of ICUs regarding 15,030 adult patients hospitalized between October 2011 and December 2014. The study group comprised 1,234 AKl individuals (8.2\%) who required RRT. The primary outcome was ICU mortality. The length of ICU stay (LOS) was considered the secondary outcome. Observed mortality was compared to that predicted by the Acute Physiology and Chronic Health Evaluation II (APACHEII).

Results. The overall mortality of the patients in the registry was 43.9\%; it was higher in AKI-RRT subjects than in non-AKI-RRT counterparts (69.4\% vs 41.0\%; $p<0.01$ ). The median APACHE II score among AKI-RRT subjects was 26 (IQR: 20-32) points. The observed mortality among AKI-RRT patients was significantly higher than predicted by APACHE II, particularly in individuals with lower baseline risk (overall difference: 14.4\%). Six patient-related variables independently predicted ICU mortality with moderate accuracy (area under the receiver operating characteristic, AUROC $=0.675 ; 95 \%$ C I $0.65-0.70)$. The ICU LOS of AKI-RRT subjects was longer than that of the controls (9.8 [IQR: 4.0-19] vs 5.7 [IQR: 2.1-12] days; $p<0.001$ ).

Conclusions. The mortality of critically ill AKI patients requiring RRT was significantly higher than in the overall ICU population. APACHE II scores underestimate mortality, especially in low-risk AKI-RRT subjects, and therefore should not be used in prognostic models in this cohort.
\end{abstract}

Key words: acute kidney injury, renal replacement therapy, intensive care unit, mortality

DOI

10.17219/acem/65066

\section{Copyright}

Copyright by Author(s)

This is an article distributed under the terms of the

Creative Commons Attribution Non-Commercial License

(http://creativecommons.org/licenses/by-nc-nd/4.0/) 


\section{Introduction}

Acute kidney injury (AKI) is a common and clinically important problem in critically ill patients treated in intensive care units (ICUs) worldwide. It remains an independent risk factor of poor outcome, particularly when the patients require renal replacement therapy (RRT).

Nisula et al. found that almost $40 \%$ of all ICU patients suffered from AKI, of whom $10 \%$ underwent RRT. ${ }^{1}$ In the Program to Improve Care in Acute Renal Disease (PICARD) trial, as many as $64 \%$ of AKI patients required RRT. $^{2}$ The PICARD study also acknowledged that AKI-RRT ICU patients constitute a unique group of patients with multiple comorbidities, often developing multiple organ failure, reaching a hospital mortality of $37 \% .^{2}$ Regarding the latter issue, Ostermann et al. reported a prevalence of acute renal failure of $7.6 \%$ according to RIFLE criteria, with a mortality rate of $56.8 \%$, which was 7 times higher than in subjects without AKI. ${ }^{3}$ Independent risk factors for mortality included advanced age, the Acute Physiology and Chronic Health Evaluation II (APACHE II) score, the number of failed organs, terminal illness, RIFLE stage, mechanical ventilation, urgent surgery, and nonsurgical reasons for admission. Interestingly, in their prospective multicenter study, Vesconi et al. reported that mortality in AKI-RRT patients was 54\%, with no difference between 2 pre-specified doses of RRT. ${ }^{4}$ Finally, in the largest multinational, multicenter study of AKI patients in ICUs to date, the Beginning and Ending Supportive Therapy for the Kidney (BEST Kidney) trial, the prevalence of AKI-RRT was 5-6\% and resulted in a mortality rate of $60 \%$, which was much higher than predicted by the Simplified Acute Physiology Score III (SAPS III). ${ }^{5}$

Surprisingly, this issue has not yet been investigated extensively in critically ill patients treated in Polish ICUs. Therefore, on the basis of data from a large registry, we sought to analyze short-term outcomes of AKI-RRT patients in a mixed ICU cohort.

\section{Material and methods}

The project was carried out as a registry observational multicenter study. Data regarding adult patients hospitalized in multidisciplinary ICUs in the Silesian Voivodship, Poland, was derived from the web-based Silesian Registry of Intensive Care Units, which works under the auspices of the Silesian Chamber of the Polish Society of Anesthesiology and Intensive Therapy. Although the registry is accessible to 37 ICUs covering 270 beds, it is voluntary and only about $50 \%$ of the units report regularly.

At the time of data extraction (December 31, 2014) there were 15,030 patients in the registry. All consecutive patients who required RRT during hospitalization in ICUs, independent of the type provided (intermittent or continuous) were screened. Exclusion criteria included pre-existing end-stage chronic kidney disease $(\mathrm{n}=186)$ and RRT initiated before admission to the ICU $(n=172)$.

The study group comprised 1,234 patients with AKI who required RRT (AKI-RRT) (8.2\% of all the subjects in the registry), hospitalized between October 2011 and December 2014. Acute kidney injury was defined as acute deterioration of kidney function requiring initiation of RRT, and corresponded to class 3 of AKI in the Acute Kidney Injury Network (AKIN) classification and class F (failure) in the RIFLE classification. ${ }^{6}$ Initiation of RRT was at the discretion of a treating physician and there was no protocol for the therapy initiation.

The available demographic and clinical data were retrieved. The data included 100 variables organized into 24 categories related to the pre-admission period, the moment of admission and the ICU stay. The primary outcome was crude ICU mortality. Observed mortality was additionally compared to mortality predicted by APACHE II scores. ${ }^{7}$ The length of ICU stay (LOS) was considered the secondary outcome.

All the data was anonymized. The study was approved by the Ethics Committee of the Medical University of Silesia and was performed in accordance with the ethical standards laid down in the 1964 Declaration of Helsinki and its later amendments. Due to the non-interventional nature of the study, the Ethics Committee waived the requirement for informed consent.

The statistical analysis was performed using licensed MedCalc statistical software v. 16.1 (MedCalc Software, Ostend, Belgium). Continuous variables were presented as median and interquartile range (IQR, i.e., 25-75 pc), whereas categorical variables were presented as percentages. All variables were tested for normal distribution using the Shapiro-Wilk test. Between-group differences for continuous variables were assessed using the KruskalWallis test; for categorical variables, the $\chi^{2}$ test was used.

The possible impact of the clinical and demographic parameters on mortality was initially screened by bivariate analyses. Odds ratios (ORs) and 95\% confidence intervals (CIs) were calculated. Variables with a p-value $<0.05$ were subjected to a multivariate analysis. The forward logistic regression method was applied. Logistic ORs with 95\% CIs were subsequently estimated. The receiver operating characteristic (ROC) curve was implemented to analyze the value of clinical parameters in predicting mortality in AKI-RRT patients. A p-value $<0.05$ was considered statistically significant.

\section{Results}

Out of 15,030 patients, 1,234 (8.2\%) developed AKI requiring RRT. The patient characteristics are shown in Table 1 . The median age of AKI-RRT patients was 66 years (IQR: 56-75); 790 of them (64\%) were male. On ICU admission, their median APACHE II score was 26 points (IQR: 20-32). 
Table 1. Pre-ICU admission clinical data

\begin{tabular}{|c|c|c|c|c|c|}
\hline Variable & $\begin{array}{c}\text { All } \\
(n=1234)\end{array}$ & $\begin{array}{l}\text { Non-survivors } \\
\quad(\mathrm{n}=856)\end{array}$ & $\begin{array}{l}\text { Survivors } \\
(n=378)\end{array}$ & OR $(95 \% \mathrm{Cl})$ & $p$-value \\
\hline Age [years] & $66(56-75)$ & $67(57-76)$ & $64(54-74)$ & $1.01(1.00-1.02)$ & $<0.001$ \\
\hline Females, n (\%) & $444(35.9)$ & $303(35.4)$ & $141(37.3)$ & $0.92(0.72-1.18)$ & 0.52 \\
\hline Hospitalization prior to ICU [days] & $2(1-7)$ & $2(1-7)$ & $2(0-6)$ & $1.01(0.99-1.02)$ & 0.049 \\
\hline Alcohol abuse, n (\%) & $132(10.7)$ & $82(9.6)$ & $50(13.2)$ & $0.69(0.48-1.01)$ & 0.057 \\
\hline Auto-aggressive systemic disease, $n$ (\%) & $35(2.8)$ & $20(2.3)$ & $15(3.9)$ & $0.58(0.29-1.14)$ & 0.116 \\
\hline Malignancies, n (\%) & $59(4.8)$ & $39(4.5)$ & $20(5.3)$ & $0.85(0.49-1.49)$ & 0.577 \\
\hline CAD, n (\%) & $609(49.3)$ & $456(53.3)$ & $153(40.5)$ & $1.68(1.31-2.14)$ & $<0.001$ \\
\hline DM, n (\%) & 384 (31.1) & $265(30.9)$ & $119(31.5)$ & $0.98(0.75-1.27)$ & 0.850 \\
\hline Cachexia (BMI< 18.5), n (\%) & $51(4.1)$ & $36(4.2)$ & $15(3.9)$ & $1.06(0.57-1.96)$ & 0.847 \\
\hline Arterial hypertension, n (\%) & $648(52.5)$ & $466(54.4)$ & $182(48.1)$ & $1.29(1.01-1.64)$ & 0.041 \\
\hline Previous stroke, n (\%) & $67(5.4)$ & $44(5.1)$ & $23(6.1)$ & $0.84(0.50-1.41)$ & 0.500 \\
\hline Solid organ transplantation, n (\%) & $8(0.06)$ & $7(0.08)$ & $1(0.03)$ & $3.11(0.38-25.4)$ & 0.289 \\
\hline CHF, n (\%) & $556(45.1)$ & $387(45.2)$ & $169(44.7)$ & $1.02(0.80-1.30)$ & 0.870 \\
\hline CKD, n (\%) & $384(31.1)$ & $269(31.4)$ & $115(30.4)$ & $1.05(0.81-1.36)$ & 0.726 \\
\hline CRF, n (\%) & $120(9.7)$ & $92(10.7)$ & $28(7.4)$ & $1.50(0.97-2.34)$ & 0.069 \\
\hline Chronic neurologic disease, n (\%) & $53(4.3)$ & $36(4.2)$ & $17(4.5)$ & $0.93(0.52-1.68)$ & 0.82 \\
\hline Atherosclerosis, n (\%) & $465(37.7)$ & $357(41.7)$ & $108(28.6)$ & $1.79(1.38-2.32)$ & $<0.001$ \\
\hline Obesity (BMI > 35), n (\%) & $83(6.7)$ & $50(5.8)$ & $33(8.7)$ & $0.65(0.41-1.02)$ & 0.06 \\
\hline
\end{tabular}

CAD - coronary artery disease; DM - diabetes mellitus; BMI - body mass index ( $\left.\mathrm{kg} \mathrm{m}^{-2}\right)$; CHF - chronic heart failure; CKD - chronic kidney disease; CRF - chronic respiratory failure.

(a)

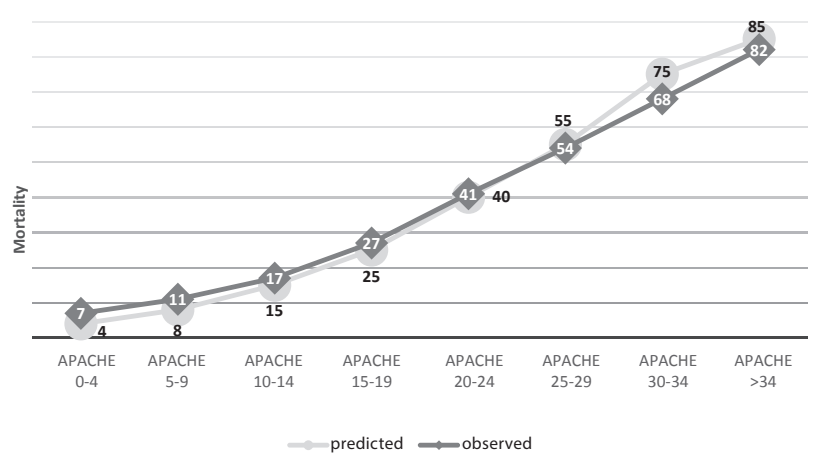

(b)

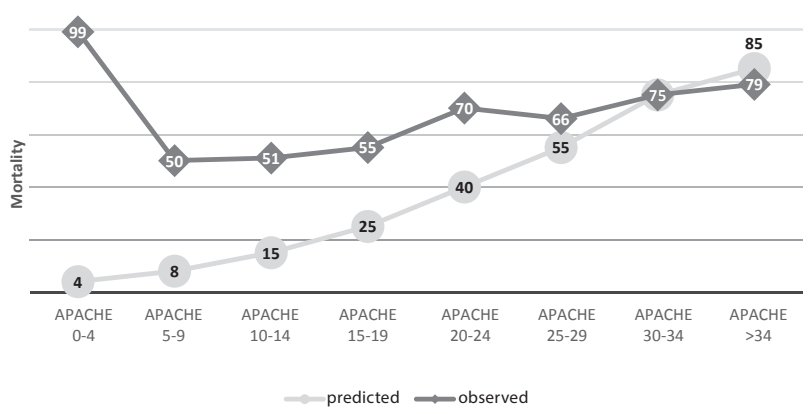

The overall mortality of the patients in the registry was 43.9\%. AKI-RRT subjects had statistically significantly higher crude ICU mortality (69.4\%) than non-AKI-RRT (c)

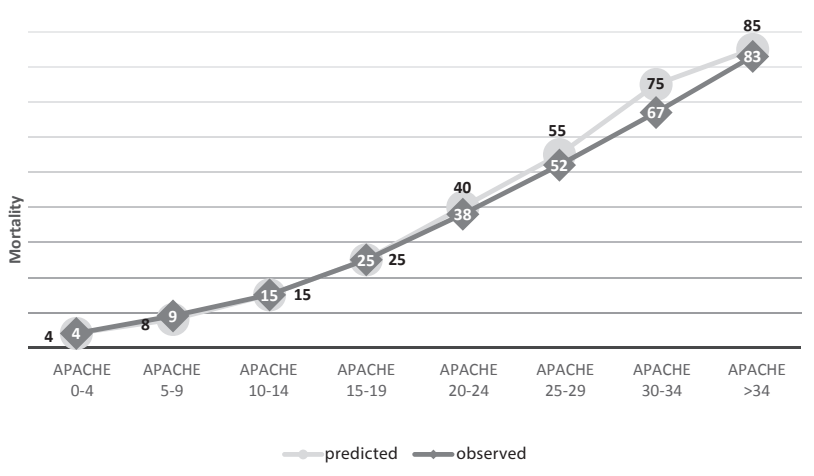

Fig. 1. Observed vs predicted mortality in all registry patients (a) and in subgroups: patients with acute kidney injury requiring renal replacement therapy (b); and patients without acute kidney injury (c) (based on Knaus et al. ${ }^{7}$ )

patients $(41.0 \%)(\mathrm{p}<0.01)$. The observed mortality in all the registry patients was comparable to that predicted by APACHE II scores, whereas a significantly higher risk 
Table 2. Primary ICU admission diagnosis

\begin{tabular}{|c|c|c|c|c|c|}
\hline Variable & $\begin{array}{c}\text { Total } \\
(\mathrm{n}=1234)\end{array}$ & $\begin{array}{c}\text { Non-survivors } \\
\quad(n=856)\end{array}$ & $\begin{array}{l}\text { Survivors } \\
(n=378)\end{array}$ & OR $(95 \% \mathrm{Cl})$ & $p$-value \\
\hline Severe sepsis, n (\%) & $232(18.8)$ & $157(18.3)$ & 75 (19.8) & $0.91(0.67-1.23)$ & 0.53 \\
\hline Severe metabolic disorder, n (\%) & $123(9.9)$ & $90(10.5)$ & $33(8.7)$ & $1.23(0.81-1.87)$ & 0.34 \\
\hline Infection, n (\%) & $277(22.4)$ & $213(24.9)$ & $64(16.9)$ & $1.62(1.19-2.22)$ & 0.002 \\
\hline Circulatory insufficiency, n (\%) & $656(53.2)$ & $508(59.3)$ & $148(39.1)$ & $2.27(1.77-2.91)$ & $<0.001$ \\
\hline MODS, n (\%) & $323(26.2)$ & $245(28.6)$ & 78 (20.6) & $1.54(1.15-2.06)$ & 0.003 \\
\hline SCA, n (\%) & $253(20.5)$ & $191(22.3)$ & $62(16.4)$ & $1.46(1.07-2.01)$ & 0.018 \\
\hline Acute respiratory failure, n (\%) & $815(66.0)$ & $603(70.4)$ & $212(56.1)$ & $1.87(1.45-2.40)$ & $<0.001$ \\
\hline Acute neurologic disease, n (\%) & $36(2.9)$ & $23(2.7)$ & $13(3.4)$ & $0.77(0.39-1.55)$ & 0.47 \\
\hline SAP, n (\%) & $56(4.5)$ & $45(5.3)$ & $11(2.9)$ & $1.85(0.95-3.62)$ & 0.07 \\
\hline Postsurgical status, n (\%) & $377(30.6)$ & $273(31.9)$ & $104(27.5)$ & $1.23(0.94-1.61)$ & 0.124 \\
\hline $\mathrm{TBI}, \mathrm{n}(\%)$ & $17(1.4)$ & $10(1.2)$ & $7(1.8)$ & $0.63(0.24-1.66)$ & 0.35 \\
\hline Multiple trauma, n (\%) & $35(2.8)$ & $15(1.7)$ & $20(5.3)$ & $0.32(0.16-0.63)$ & 0.001 \\
\hline Shock, n (\%) & $492(39.9)$ & $386(45.1)$ & $106(28.0)$ & $2.11(1.62-2.73)$ & $<0.001$ \\
\hline Obtunded consciousness, n (\%) & $446(36.1)$ & $352(41.1)$ & $94(24.9)$ & $2.11(1.61-2.76)$ & $<0.001$ \\
\hline Acute on chronic respiratory failure, $\mathrm{n}(\%)$ & $63(5.1)$ & $44(5.1)$ & $19(5.0)$ & $1.02(0.59-1.78)$ & 0.93 \\
\hline Poisoning, n (\%) & $24(1.9)$ & $16(1.9)$ & $8(2.1)$ & $0.88(0.37-2.08)$ & 0.77 \\
\hline
\end{tabular}

MODS - multiple organ dysfunction syndrome; SCA - sudden cardiac arrest; SAP - severe acute pancreatitis; TBI - traumatic brain injury.

Table 3. Direct ICU admission diagnosis

\begin{tabular}{|c|c|c|c|c|c|}
\hline Variable & $\begin{array}{c}\text { Total } \\
(\mathrm{n}=1234)\end{array}$ & $\begin{array}{l}\text { Non-survivors } \\
\quad(n=856)\end{array}$ & $\begin{array}{l}\text { Survivors } \\
(n=378)\end{array}$ & OR $(95 \% \mathrm{Cl})$ & $\mathrm{p}$-value \\
\hline Circulatory insufficiency, n (\%) & $952(77.3)$ & $704(82.2)$ & $248(65.6)$ & $2.43(1.84-3.20)$ & $<0.001$ \\
\hline Renal failure, n (\%) & $691(56.0)$ & $480(56.1)$ & $211(55.8)$ & $1.01(0.79-1.29)$ & 0.93 \\
\hline Respiratory failure, n (\%) & $1087(88.1)$ & $775(90.5)$ & $312(82.5)$ & $2.02(1.42-2.87)$ & $<0.001$ \\
\hline Multiple trauma, n (\%) & $38(3.1)$ & $17(2.0)$ & $21(5.6)$ & $0.34(0.18-0.66)$ & 0.001 \\
\hline Metabolic disorders, n (\%) & $516(41.8)$ & $376(43.9)$ & $140(37.0)$ & $1.33(1.04-1.71)$ & 0.024 \\
\hline Obtunded consciousness, n (\%) & $695(56.3)$ & $507(59.2)$ & $188(49.7)$ & $1.47(1.15-1.87)$ & 0.002 \\
\hline
\end{tabular}

of death was found among AKI-RRT patients than was predicted by the score, particularly in low-risk categories of patients (Fig. 1). The median ICU LOS was 12.8 days (IQR: 7.5-21.9). This was longer in AKI-RRT subjects than in the controls (9.8 days [IQR: $4.0-19]$ vs 5.7 days [IQR: 2.1-12], respectively]; $\mathrm{p}<0.001$ ).

By bivariate analyses we identified 31 potential risk factors for mortality in AKI-RRT patients. The non-survivors were significantly older than the survivors (67 years [IQR: 57-76] vs 64 years [IQR: $54-74]$; $\mathrm{p}<0.001$ ). All between-group differences regarding demographics, parameters upon ICU admission and ICU stay are presented in Tables 2-5. The non-survivors scored higher on APACHE II (27 points [IQR: $21-32$ ] vs 24 points [IQR: $18-30$ ]; $\mathrm{p}<0.001$ ), SAPS III (66 [IQR: 45-84] vs 60 points [IQR: 44-76]; $\mathrm{p}=0.003$ ) and the simplified Therapeutic Intervention Scoring System 28 (TISS-28) during the first $24 \mathrm{~h}$ (39 points [IQR: $34-45]$ vs 38 points [IQR: $32-44] ; \mathrm{p}=0.014)$. The Glasgow Coma Scale (GCS) score in the non-survivors was lower than in the survivors (6 points [IQR: $3-12$ ] vs 10 points [IQR: $5-14] ; \mathrm{p}<0.001)$.
ICU LOS was significantly shorter in the non-survivors than in the survivors ( 8 days [IQR: $2.8-17.6$ ] vs 12.8 days [IQR: 7.5-21.9]; $\mathrm{p}<0.001$ ]. The 2 groups also differed significantly with regard to the duration of hospitalization prior to ICU admission, with the non-survivors being treated outside the ICU for longer periods of time (2 days [IQR: $1-7]$ vs 2 days [IQR: 0-6]; $\mathrm{p}=0.049$ ).

In a logistic regression model, only 6 variables were named as independent determinants of mortality in AKI-RRT patients (Fig. 2) with an area under the ROC curve (AUROC) of 0.675 (95\% CI 0.65-0.70).

\section{Discussion}

On the basis of data from a large registry, we conducted an in-depth investigation of mortality among AKI patients requiring RRT in ICUs. Our study showed high hospital mortality (69.4\%) among AKI-RRT patients, which was significantly higher than predicted by an acknowledged 
Table 4. Clinical data upon ICU admission

\begin{tabular}{|c|c|c|c|c|c|}
\hline Variable & $\begin{array}{c}\text { Total } \\
(\mathrm{n}=1234)\end{array}$ & $\begin{array}{c}\text { Non-survivors } \\
\quad(n=856)\end{array}$ & $\begin{array}{l}\text { Survivors } \\
(\mathrm{n}=378)\end{array}$ & OR $(95 \% \mathrm{Cl})$ & $p$-value \\
\hline GCS score & $7(3-13)$ & $6(3-12)$ & $10(5-14)$ & $0.92(0.89-0.95)$ & $<0.001$ \\
\hline APACHE $\|^{*}$ & $26(20-32)$ & $27(21-32)$ & $24(18-30)$ & $1.04(1.02-1.06)$ & $<0.001$ \\
\hline SAPS \|\|$^{*}$ & $64(45-81)$ & $66(45-84)$ & $60(44-76)$ & $1.01(1.00-1.02)$ & 0.003 \\
\hline 24 h TISS-28* & $39(33-45)$ & $39(34-45)$ & $38(32-44)$ & $1.02(1.01-1.04)$ & 0.014 \\
\hline Catecholamine use, n (\%) & $718(58.2)$ & $536(62.6)$ & $182(48.1)$ & $1.80(1.41-2.30)$ & $<0.001$ \\
\hline Obtunded consciousness, n (\%) & $798(64.7)$ & $594(69.4)$ & $204(53.9)$ & $1.93(1.51-2.48)$ & $<0.001$ \\
\hline Endocavitary stimulation, n (\%) & $19(1.5)$ & $14(1.6)$ & $5(1.3)$ & $1.24(0.44-3.47)$ & 0.68 \\
\hline Mechanical ventilation, n (\%) & $882(71.5)$ & $648(75.7)$ & $234(61.9)$ & $1.92(1.48-2.49)$ & $<0.001$ \\
\hline Intubated, n (\%) & 887 (71.9) & $654(76.4)$ & $233(61.6)$ & $2.01(1.55-2.61)$ & $<0.001$ \\
\hline
\end{tabular}

GCS - Glasgow Coma Scale; APACHE II - Acute Physiology and Chronic Health Evaluation II; SAPS III - Simplified Acute Physiology Score III; TISS-28 -

Therapeutic Intervention Scoring System 28; * calculations based on the worst values recorded during the first $24 \mathrm{~h}$ post ICU admission.

Table 5. Clinical data during ICU stay

\begin{tabular}{|c|c|c|c|c|c|}
\hline Variable & $\begin{array}{c}\text { Total } \\
(n=1234)\end{array}$ & $\begin{array}{l}\text { Non-survivors } \\
\qquad(\mathrm{n}=856)\end{array}$ & $\begin{array}{l}\text { Survivors } \\
(\mathrm{n}=378)\end{array}$ & OR $(95 \% \mathrm{Cl})$ & $\mathrm{p}$-value \\
\hline Catecholamine use, n (\%) & $1158(93.8)$ & $832(97.2)$ & $326(86.2)$ & $5.53(3.35-9.12)$ & $<0.001$ \\
\hline Antibiotics, n (\%) & $1146(92.9)$ & $799(93.3)$ & $347(91.8)$ & $1.25(0.79-1.97)$ & 0.333 \\
\hline CRRT, n (\%) & $1092(88.5)$ & $764(89.2)$ & $328(86.8)$ & $1.27(0.88-1.83)$ & 0.209 \\
\hline IHD, n (\%) & $208(16.9)$ & $141(16.5)$ & $67(17.7)$ & $0.91(0.66-1.26)$ & 0.588 \\
\hline ECMO, n (\%) & $21(1.7)$ & $18(2.1)$ & $3(0.8)$ & $2.68(0.79-9.17)$ & 0.115 \\
\hline IABP, n (\%) & $79(6.4)$ & $67(7.8)$ & $12(3.2)$ & $2.59(1.38-4.85)$ & 0.003 \\
\hline Surgery in ICU, n (\%) & $275(22.3)$ & $202(23.6)$ & $73(19.3)$ & $1.29(0.96-1.74)$ & 0.096 \\
\hline Tracheostomy, n (\%) & $287(23.3)$ & $194(22.7)$ & $93(24.6)$ & $0.89(0.68-1.19)$ & 0.457 \\
\hline Invasive ventilation, n (\%) & $1070(86.7)$ & $761(88.9)$ & $309(81.7)$ & $1.79(1.28-2.51)$ & $<0.001$ \\
\hline Non-invasive ventilation, n (\%) & $81(6.6)$ & $33(3.9)$ & $48(12.7)$ & $0.28(0.17-0.44)$ & $<0.001$ \\
\hline
\end{tabular}

CRRT - continuous renal replacement therapy; IHD - intermittent hemodialysis; ECMO - extracorporeal membrane oxygenation; IABP - intra-aortic balloon pump counter-pulsation.

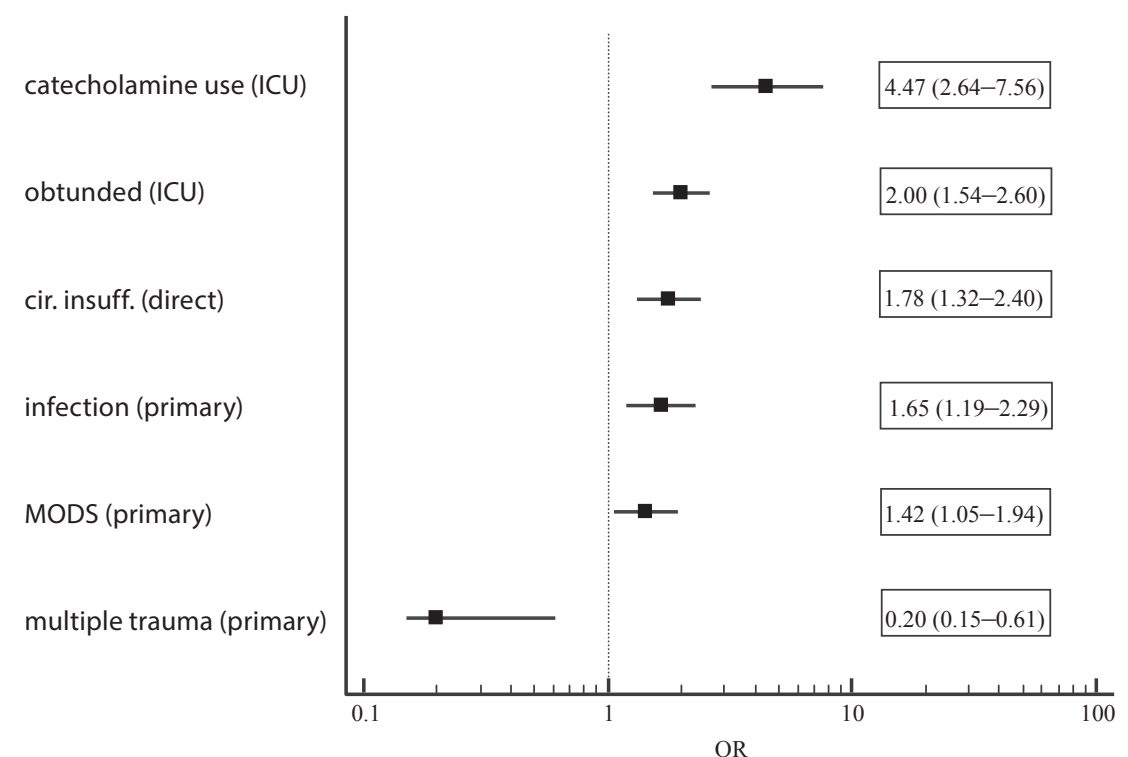

Fig. 2. Independent predictors of mortality in patients with AKI requiring RRT

In boxes on the right-hand side: logistic ORs and 95\% Cls.In brackets on the left-hand side: direct - direct reason for ICU admission; ICU - data covering entire ICU stay; primary - primary diagnosis upon ICU admission; ICU - intensive care unit; MODS - multiple organ dysfunction syndrome. 
method, i.e., APACHE II score (a difference of 14.4\%). We also identified 5 risk factors for this compromised outcome.

Acute kidney injury is a worldwide problem that frequently occurs in the ICU setting. Irrespective of its nature, this clinical phenomenon often has a heterogeneous etiology and difficult, mainly supportive, management. First, it is strongly recommended to stratify all patients at risk of AKI according to their susceptibilities and exposures. ${ }^{6}$ However, when preventive and treatment strategies are ineffective in halting the progression of AKI, RRT should be initiated to avoid life-threatening changes in the fluid, electrolyte, and acid-base balance. Additionally, AKI occurrence and its sequelae may be difficult to predict by simple statistical algorithms.

Our main results are in line with previous international findings in AKI ICU patients ${ }^{3,5}$; however, it should be borne in mind that RRT has in itself been confirmed to be an independent risk factor for mortality. ${ }^{8}$ This may explain the discrepancy between the observed and predicted death rates previously revealed in the BEST Kidney trial. ${ }^{5}$ However, Bagshaw et al. opposed this assumption, showing that RRT-treated patients were fundamentally different from non-treated patients across a spectrum of variables, causing a possible bias in observational data. ${ }^{9}$ Remarkably, it has been emphasized that mortality prognostication using APACHE II scores can depend on the population studied and may be associated with substantial errors. ${ }^{10}$

More compliant findings relate to possible predictors of death. In our study, the use of any catecholamines (vasopressors, inotropic agents) was associated with the greatest increase in mortality in AKI-RRT patients (i.e., 4.5 times). Independently, circulatory failure as a direct admission diagnosis increased the mortality risk almost 2 -fold $(\mathrm{OR}=1.78)$. On the one hand, the use of catecholamines is demanded by a patient's poor circulatory condition, revealed by hypotension and decreased heart function. On the other hand, its institution may lead to hemodynamic instability. Both scenarios promote renal hypoperfusion, which has been reported as a key risk factor for AKI. ${ }^{11}$ The use of vasopressors per se may also be associated with a poor prognosis in patients with severe AKI. ${ }^{12}$ Additionally, patients with hemodynamic instability often receive excessive amounts of fluid to optimize cardiac output, especially when there is no hemodynamic algorithm in place. As it happens, fluid overload has been confirmed to increase mortality, including in AKI-RRT patients. ${ }^{13,14}$

In our study, significant infection as a direct reason for admission was also associated with higher mortality in AKI-RRT patients $(\mathrm{OR}=1.65)$. It is well-known that septic patients more frequently develop AKI, require RRT, have higher mortality and ICU LOS. ${ }^{15}$ About $40 \%$ of septic subjects develop AKI and 50\% of all AKI may be related to sepsis. ${ }^{16}$ Moreover, sepsis has been found to be an independent predictor of mortality in AKI-RRT patients with traumatic brain injury. ${ }^{17}$ Interestingly, hemodynamic failure may exacerbate the deleterious effect of sepsis. The duration of mean arterial pressure below $65 \mathrm{~mm} \mathrm{Hg}$, the daily fluid balance, the number of days on vasopressors, and high doses of vasopressors were associated with worse outcomes. $^{18}$

Interestingly, AKI-RRT patients hospitalized due to multiple trauma had lower mortality. Traumatic patients are likely to have fewer factors predisposing to AKI in the pre-admission period, and hence their renal dysfunction is usually reversible. This is in agreement with data showing that AKI in this population is rare. ${ }^{19}$

Our study has several limitations. Firstly, the final prediction model had only moderate diagnostic accuracy. Taking into consideration the fact that we thoroughly investigated a broad spectrum of variables, the most probable explanation for this is the heterogeneous pathophysiology of AKI in our ICU cohort. Secondly, we lacked some important clinical data that might have influenced the outcomes in the AKI-RRT population, including creatinine concentration, fluid balance, the timing of RRT, or trending in RIFLE classifications. However, entering all these additional parameters into a large database would require enormous effort on the part of attending physicians and potentially discourage them from reporting. It must be borne in mind that reporting to this registry is entirely voluntary, and that the registry was not set up specifically to research AKI. Next, there were no accurate definitions for some conditions given, e.g., the broad term 'shock' without specifying what type of shock should be considered: cardiogenic, hemorrhagic, anaphylactic, etc. The observational nature of our project is an obvious limitation of all registries, as it may lead to a systematic error. Additionally, the registry covers only 1 region in Poland and is not representative of the whole country. Finally, only $40-50 \%$ of Silesian ICUs report to the registry on a regular basis. However, the large number of patients analyzed may alleviate this drawback. Even when all of these shortcomings are considered, the clinical evidence presented above should be of interest to an international audience, as it is the first in-depth insight into the problem of AKIRRT in Polish ICUs.

\section{Conclusions}

Mortality among critically ill AKI patients requiring RRT is significantly higher than in the overall ICU population. APACHE II scores underestimate mortality, especially in low-risk AKI-RRT subjects, and therefore should not be used in prognostic models in this cohort. Although it is difficult to accurately identify all the predictors of the compromised outcome in this unique population, the prognosis of patients with multiple trauma is the most favorable. 


\section{References}

1. Nisula S, Kaukonen KM, Vaara ST, et al. Incidence, risk factors and 90-day mortality of patients with acute kidney injury in Finnish intensive care units: The FINNAKI study. Crit Care Med. 2013;39:420-428.

2. Mehta RL, Pascual MT, Soroko S, et al. Spectrum of acute renal failure in the intensive care unit: The PICARD experience. Kidney Int. 2004;66:1613-1621.

3. Ostermann M, Chang RW. Acute kidney injury in the intensive care unit according to RIFLE. Crit Care Med. 2007;35:1837-1843.

4. Vesconi S, Cruz DN, Fumagalli R, et al. Delivered dose of renal replacement therapy and mortality in critically ill patients with acute kidney injury. Crit Care. 2009;13:R57.

5. Uchino S, Bellomo R, Morimatsu $\mathrm{H}$, et al. The beginning and ending supportive therapy for the kidney (B.E.S.T. kidney) investigators. Continuous renal replacement therapy: A worldwide practice survey. Intens Care Med. 2007;33:1563-1570.

6. Kidney Disease: Improving Global Outcomes (KDIGO) Acute Kidney Injury Work Group. KDIGO Clinical Practice Guideline for Acute Kidney Injury. Kidney Int Suppl. 2012;2:1-138.

7. Knaus WA, Draper EA, Wagner DP, Zimmerman JE. APACHE II: A severity of disease classification system. Crit Care Med. 1985;13:818-829.

8. Elseviers MM, Lins RL, Van der Niepen P, et al. Renal replacement therapy is an independent risk factor for mortality in critically ill patients with acute kidney injury. Crit Care. 2010;14:R221.

9. Bagshaw SM, Uchino S, Kellum JA, et al. Association between renal replacement therapy in critically ill patients with severe acute kidney injury and mortality. J Crit Care. 2013;28:1011-1118.

10. Śmiechowicz J. Prognostic scoring systems for mortality in intensive care units: the APACHE model. Anaesthesiol Intensive Ther. 2015;47: 87-88.
11. Clec'h C, Razafimandimby D, Laouisset M, Chemouni F, Cohen Y. Incidence and outcome of contrast-associated acute kidney injury in a mixed medical-surgical ICU population: A retrospective study. BMC Nephrol. 2013;4:14-31.

12. Mehta RL, Kellum JA, Shah SV, et al. Acute kidney injury network. Report of an initiative to improve outcomes in acute kidney injury. Crit Care. 2007;11(2):R31.

13. Payen D, de Pont AC, Sakr Y, Spies C, Reinhart K, Vincent JL. A positive fluid balance is associated with a worse outcome in patients with acute renal failure. Crit Care. 2008;12:R74.

14. Xu J, Shen B, Fang Y, et al. Postoperative fluid overload is a useful predictor of the short-term outcome of renal replacement therapy for acute kidney injury after cardiac surgery. Medicine. 2015;94(33):e1360.

15. Piccinni P, Cruz DN, Gramaticopolo S, et al. Prospective multicenter study on epidemiology of acute kidney injury in the ICU: A critical care nephrology Italian collaborative effort (NEFROINT). Minerva Anestesiol. 2011;77:1072-1083.

16. Uppalapati A, Kellum JA. The critically ill patient with acute kidney injury. In: Kellum JA, Bellomo R, Ronco C, eds. Continuous Renal Replacement Therapy. $2^{\text {nd }}$ ed. New York, NY: Oxford University Press; 2010 [e-book].

17. Lopes JA, Jorge S, Resina C, et al. Acute kidney injury in patients with sepsis: A contemporary analysis. Int J Infect Dis. 2009;13:176-181.

18. Wang $X$, Jiang $L$, Wen $Y$, et al. Risk factors for mortality in patients with septic acute kidney injury in intensive care units in Beijing, China: A multicenter prospective observational study. Biomed Res Int. 2014;2014:172620. doi:10.1155/2014/172620

19. Beitland S, Moen H, Os I. Acute kidney injury with renal replacement therapy in trauma patients. Acta Anaesth Scand. 2010;54:833-840. 